\title{
Coulisses
}

Revue de théâtre

12 | Printemps 1995

Varia

\section{Témoignage : le BELT - Besançon English Language Theatre}

Andrew Rossiter

\section{(2) OpenEdition}

12 Journals

Édition électronique

URL : http://journals.openedition.org/coulisses/3481

DOI : 10.4000/coulisses.3481

ISSN : 2546-9460

Éditeur

Presses universitaires de Franche-Comté

\section{Édition imprimée}

Date de publication : 1 mai 1995

Pagination : 86

ISSN : 1150-594X

\section{Référence électronique}

Andrew Rossiter, «Témoignage : le BELT - Besançon English Language Theatre », Coulisses [En ligne], 12 | Printemps 1995, mis en ligne le 15 mars 2019, consulté le 31 octobre 2019. URL : http:// journals.openedition.org/coulisses/3481; DOI : 10.4000/coulisses.3481

Ce document a été généré automatiquement le 31 octobre 2019.

Coulisses 


\title{
Témoignage : le BELT - Besançon English Language Theatre
}

\author{
Andrew Rossiter
}

1 Le théâtre universitaire est une institution incontournable dans presque toute université anglo-saxonne ; même au sein d'universités technologiques ou scientifiques, le théâtre a souvent sa place. Par théâtre universitaire, cependant, il faut comprendre théâtre organisé, géré et dirigé à $100 \%$ par des étudiants; rare sont les théâtres universitaires dirigés par des enseignants - sauf les théâtres en langue étrangère.

2 L'idée d'un théâtre anglais à la Faculté des Lettres de Besançon fut lancée dès 1983 par Andrew Rossiter, alors lecteur au département de langues vivantes. L'objectif était triple :

- Faire du théâtre, et donner l'occasion d'en faire.

- Donner aux étudiants l'occasion de voir du théâtre en anglais.

- Atteindre un but pédagogique plus large, en ouvrant ce théâtre aux lycées.

Le projet a démarré immédiatement, sans subvention, et la première production, en mars 1974, The Importance of Being Earnest, d'Oscar Wilde, a remporté un vif succès.

Depuis cette première production, présentée il y a 21 ans dans un «théâtre » créé de toutes pièces, avec les moyens du bord, dans l'ancienne salle 24, le BELT présente régulièrement une pièce par an - sinon deux. Parmi les plus réussies de ces productions ont figuré A Streetcar Named Désire de Tenessee Williams, A Delicate Balance d'Albee, Charley's Aunt (la plus célèbre farce anglaise) de Brandon Thomas, Blithe Spirit de Noel Coward, The Heiress, d'après Henry James et Billy Liar, de Willis Hall.

Depuis Gaslight de Patrick Hamilton, mis en scène en 1987 par Andrew Rossiter et Lee Gainer, le BELT a présenté The Homecoming et The Birthday party de Pinter, le très célèbre Mousetrap d'Agatha Christie, et une comédie de Terrence Rattigan French without Tears. En tout, le BELT a monté 25 pièces.

Quant aux comédiens qui, au fil des années, ont joué au sein de ce théâtre universitaire, la plupart ont été anglophones. Si beaucoup avaient une certaine expérience du théâtre universitaire, certains ont fait leurs premiers pas sur les planches en jouant avec le 
BELT ; d'autres prévoyaient même de faire une carrière sur la scène sinon à Hollywood. Grâce au CLA, le BELT a même pu accueillir quelques professionnels, ou exprofessionnels, en stage de français à Besançon - une ancienne de la Compagnie Old Vic de Londres, un metteur en scène " off Broadway », une ancienne de la Young National Theatre anglais.

7 Vraisemblablement, l'histoire de BELT doit le placer au premier rang des théâtres universitaires anglophones de France. 